\title{
Powerful GC-TOF-MS Techniques for Screening, Identification and Quantification of Halogenated Natural Products
}

\author{
Peter S. Haglund, ${ }^{* 1}$ Karin Löfstrand, ${ }^{2}$ Kevin Siek, ${ }^{3}$ and Lillemor Asplund ${ }^{4}$ \\ ${ }^{1}$ Department of Chemistry, Umeå University, 90187 Umeå, Sweden \\ ${ }^{2}$ Department of Applied Environmental Science, Stockholm University, 11418 Stockholm, Sweden \\ ${ }^{3}$ Leco Corporation, Saint Joseph, MI 49085, USA \\ ${ }^{4}$ Department of Materials and Environmental Chemistry, Stockholm University, 10691 Stockholm, Sweden
}

\begin{abstract}
Comprehensive two-dimensional gas chromatography/time-of-flight mass spectrometry (GC $\times$ GC TOFMS) and gas chromatography/high-resolution time-of-flight mass spectrometry (GC-HRT) were used to detect and identify halogenated natural products (HNPs) in tissue homogenate, in this case brominated analytes present in a marine snail. Two classes of brominated anthropogenic compounds, polybrominated diphenyl ethers (PBDEs) and brominated dibenzofurans, were analyzed for comparison. Following conventional preparation, the sample was analyzed using GC $\times$ GC-TOF-MS. Isotope ratio scripts were used to compile a list of putatively brominated analytes from amongst the thousands of features resolved in the twodimensional chromatogram. The structured nature of the chromatogram was exploited to propose identifications for several classes of brominated compounds, and include additional candidates that fell marginally outside the script tolerances. The sample was subsequently analyzed by GC-HRT. The high-resolution mass spectral data confirmed many formula assignments, facilitated confident assignment of an alternate formula when an original proposal did not hold, and enabled unknown identification. Identified HNPs include hydroxylated and methoxylated PBDE analogs, polybrominated dibenzo- $p$-dioxins (PBDDs) and hydroxyl-PBDDs, permitting the environmental occurrence and fate of such compounds to be studied.
\end{abstract}

Keywords: GC $\times$ GC, multi-reflectron TOF, halogenated natural products, dioxins, screening, emerging pollutants

(Received November 1, 2012; Accepted January 15, 2013)

\section{INTRODUCTION}

Environmental samples often present a challenging task to the analytical chemists. The target compounds are generally present at trace levels in a complex cocktail of natural and anthropogenic compounds. In order to accurately quantify such trace compounds it is essential to reduce the background, but also to efficiently separate the target compounds from each other and residual matrix.

Over the last decades, comprehensive two-dimensional GC $(\mathrm{GC} \times \mathrm{GC})$ has evolved into a robust and exceptionally powerful technique for group-type as well as within-group (isomer) separations. By employing two columns with, e.g. a non-polar and a polar stationary phase, two independent modes of separations are utilized (volatility and polarity) to allow all compounds to become dispersed in a $2 \mathrm{D}$ space. A modulator (most often based on cryogenic cooling) is used to focus and release packages of material for a second separation, which has to be fast in order to obtain multiple samplings of each first-dimension peak. This calls for the use of a rapid detector, in this case a TOFMS. Group-type separations of petroleum hydrocarbons were one of the first and most important areas of application. ${ }^{1)}$ In the case of isomer separations, one of the more demanding tasks is the complete separation of the 209 PCBs or 210 polychlorinated dioxins and furans (PCDD/Fs). ${ }^{2)}$

Most analytical methods for persistent organic pollutants
(POPs) focus on individual groups of targeted analytes. Therefore, analysis of multiple classes of POPs typically entails several sample preparations, fractionations, and injections, whereas other chemicals of possible interest are neglected or lost. To analyze a wider scope of organic contaminants $\mathrm{GC} \times \mathrm{GC}$ time-of-flight mass spectrometry (TOF-MS) may be employed to samples that have undergone a minimum of sample clean-up. This approach was used by Hoh et al. to analyze fish oil for known POPs and, simultaneously, screen for and tentatively identify multiple groups of halogenated natural products (HNPs). ${ }^{3)}$ However, the complexity of this type of extracts is overwhelming and the data evaluation very time consuming. It is therefore a clear need for automatic procedures to screen for groups of compounds that share structural features, such as chlorines or bromines in HNPs.

In the current paper we describe an automatic $\mathrm{GC} \times \mathrm{GC}$ TOF-MS procedure to screen organisms with low metabolic capacity (crustacean) for brominated (natural) products. It was complemented with ultra-high resolution GC-TOFMS, utilizing a novel folded flight path TOF analyzer, which deliver full-scan spectra at a resolution of up to 50,000 (full width at half maximum; FWHM; over a 4 -fold mass range) and a mass precision of $1 \mathrm{ppm}$. This was used to confirm or reject tentative structures and enhanced the possibility to perform manual interpretation. Finally, the new and emerging brominated compounds were semi-quantified, and their levels compared to legacy POPs and established HNPs.

* Correspondence to: Peter S. Haglund, Department of Chemistry, Umeå Uni-

versity, 90187 Umeå, Sweden, e-mail: peter.haglund@chem.umu.se 


\section{EXPERIMENTAL}

\section{Sampling and extraction}

A marine snail (Diloma subrostrata) sample was collected from the Auckland estuary through NIWA, Auckland, New Zealand. It was freeze-dried and $1.5 \mathrm{~g}$ of the resulting tissue homogenate was fortified with an internal standard (IS) mixture containing 4'-methoxy-2,3',4,5',6pentabromodiphenyl ether and $4^{\prime}$-hydroxy-2, $3^{\prime}, 4,5^{\prime}, 6$ pentabromodiphenyl ether and ${ }^{13} \mathrm{C}_{12}$-2,3,7,8-tetrachlorodibenzo-p-dioxin (TCDD) and was extracted by accelerated solvent extraction (ASE) using three extraction cycles of dichloromethane $\left(100^{\circ} \mathrm{C} ; 1500\right.$ psi, static $5 \mathrm{~min}$, flush $60 \%$, nitrogen Purge $60 \mathrm{~s}$ ). The extract was rotary evaporated to ca. $2-3 \mathrm{~mL}$ and transferred to amber glass ampoules, sealed, and shipped to Umeå University (UmU).

\section{Clean-up}

The sample was solvent exchanged to $n$-hexane and neutral and phenolic compounds separated by partitioning with potassium hydroxide. ${ }^{4)}$ Following acidification with hydrochloric acid, the phenolic analytes were re-extracted out of the aqueous phase using $n$-hexane/methyl tert-butyl ether $(9: 1, v / v)$, derivatized with diazomethane, and used by $\mathrm{UmU}$ for screening of brominated phenolic compounds and by Stockholm University (SU) for analysis of hydroxylated polybrominated diphenyl ethers (OH-PBDEs).

The base-neutral fraction were split (50-50). One half was used by SU for analysis of PBDEs and methoxy-PBDEs (MeO-PBDEs), the other by UmU for analysis of polybrominated dibenzo- $p$-dioxin (PBDD). Lipids were removed from both fractions by partitioning between $n$-hexane and concentrated sulfuric acid. Further cleanup was achieved using a column with silica/sulfuric acid $(2 / 1, w / w)$ and a column with pure silica gel (activated over night at $300^{\circ} \mathrm{C}$ ). ${ }^{5)}$ The columns were eluted with dichloromethane.

A quantification standard was also prepared by adding well-known amounts of reference standards to GC vials that had been prepared and spiked with the internal standard in the same way as the samples. The OH-PBDE and MeO-PBDE compounds were all synthesized in house as described elsewhere. ${ }^{6)}$ The standard mixture used for quantification of PBDDs contained 2,7/2,8-diBDD; 1,3,7-, 1,3,8-, and 2,3,7-triBDD; and 1,3,6,8-, 1,3,7,9-, 1,3,7,8-, 1,2,4,7/1,2,4,8-, 1,2,3,7-, 1,2,3,8-, and 2,3,7,8-tetraBDD.

Blank samples were extracted following the same scheme as the samples, and the quantification standards and blanks were analyzed in parallel with the samples. The levels found in the blanks were negligible $(<1 \%)$ in comparison to the amounts detected in the samples.

\section{Instrumental analysis}

$G C \times G C$-screening of brominated compounds

The very complex (methylated) phenolic fraction was screened for brominated compounds using a Pegasus 4D (Leco Corp., St. Joseph, MI, USA) GC $\times$ GC-low resolution time-of-flight (TOF) MS equipped with an Agilent Technologies 6890 gas chromatograph (Palo Alto, CA, USA), a secondary GC oven, and a dual-stage jet modulator. ${ }^{7)}$ The injector temperature was maintained at $250^{\circ} \mathrm{C}$ and the transfer line and ion source temperatures at $350^{\circ} \mathrm{C}$ and $250^{\circ} \mathrm{C}$, respectively. Instrument control, and data acquisition $(100 \mathrm{~Hz})$ and processing were carried out using Chroma-TOF software (version 4.32; LECO Corp.). The $\mathrm{GC} \times \mathrm{GC}$ separation was achieved using a DB-XLB $(30 \mathrm{~m} \times 0.250 \mathrm{~mm} \times 0.25 \mu \mathrm{m}$; non-polar proprietary phase; Agilent/J\&W Scientific, Santa Clara, CA, USA) firstdimension column and a BPX-50 $(1.5 \mathrm{~m} \times 0.15 \mathrm{~mm} \times 0.15 \mu \mathrm{m}$; 50\%-phenyl polysilphenylene-siloxane; SGE, Ringwood, Australia) second-dimension column. Ion source was operated at $70 \mathrm{eV}$. Helium was used as the carrier gas at $1.4 \mathrm{~mL} /$ min. Following splitless injection of a $1 \mu \mathrm{L}$ sample aliquot, the primary GC oven temperature was kept constant at $60^{\circ} \mathrm{C}$ for $1 \mathrm{~min}$, raised at $4^{\circ} \mathrm{C}$ per minute to $340^{\circ} \mathrm{C}$, and was held isothermal for $3 \mathrm{~min}$. The secondary oven temperature was programmed as the primary oven with a $+20^{\circ} \mathrm{C}$ offset. The modulation period was set to $2 \mathrm{~s}$ with a $0.6 \mathrm{~s}$ hot pulse and $0.4 \mathrm{~s}$ lag time between cooling stages.

\section{$G C \times G C$ data evaluation}

The data was preprocessed in Chroma-TOF using the peak find and peak and spectra deconvolution software routines. Its Visual Basic scripting features was then used to automatically screen the data for bromine containing compounds. The scripting was based on the ideas of Hilton, ${ }^{8)}$ but was adopted to find mono- through octa-bromo molecular ion isotope distribution patterns. In short, the scripts work in the following way. The spectrum associated with each peak in the peak table was searched starting from the high mass end. When a peak was found with an intensity above 100 (arbitrary units) and a relative abundance above 20\% (versus the base peak) it was screened for the presence of bromine isotopes. For instance, a dibromo pattern should fulfill the ratio criteria $\mathrm{M}^{+} /[\mathrm{M}+2]^{+}$should be 0.48 to 0.58 , $[\mathrm{M}+4]^{+} /[\mathrm{M}+2]^{+}$should be 0.43 to 0.53 , and $[\mathrm{M}+3]^{+} /[\mathrm{M}+2]^{+}$ should be $<0.25$. The script used to find dibromo-HNCs is shown below:

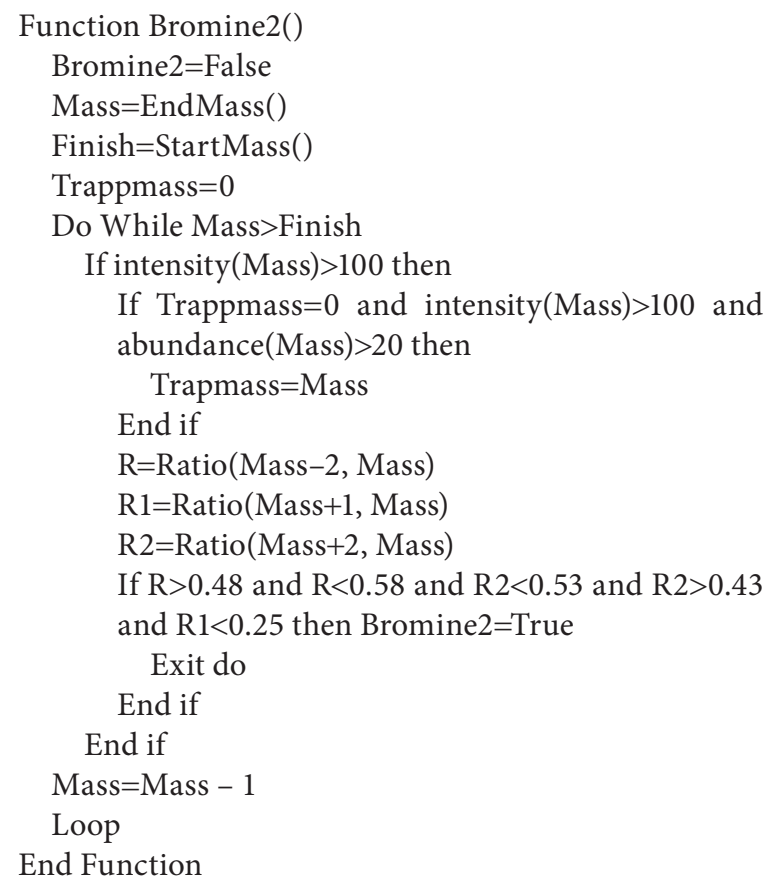

The other scripts follow the same format, but use other acceptance criteria. 


\section{GC-high-resolution TOF-MS}

Validation of tentatively identified compounds was performed using a GC-HRT (Leco Corp., St. Joseph, MI, USA) equipped with a Agilent 7890. GC separations were performed using an Rxi-5Sil MS $(60 \mathrm{~m} \times 0.18 \mathrm{~mm} \times 0.10 \mu \mathrm{m}$; Restek, Bellefonte, PA, USA) column and helium as the carrier gas at $1.0 \mathrm{~mL} / \mathrm{min}$ (constant flow mode). Injections of $1 \mu \mathrm{L}$ aliquots were made in the splitless mode with a $60 \mathrm{~s}$ purge delay and the GC oven was temperature programmed as follows: $80^{\circ} \mathrm{C}$ for $1 \mathrm{~min}$, raise at $30^{\circ} \mathrm{C} / \mathrm{min}$ to $160^{\circ} \mathrm{C}$, and raise at $3^{\circ} \mathrm{C} / \mathrm{min}$ to $270^{\circ} \mathrm{C}$ (selected to cover the $\mathrm{GC} \times \mathrm{GC}$ target analytes). The GC column was directly interfaced to the MS ion source $\left(300^{\circ} \mathrm{C}\right)$ using a transfer line heated to $300^{\circ} \mathrm{C}$. Electron ionization was performed at $74 \mathrm{eV}$ ionization energy (reduced to enhance molecular ion intensity) and full scan data was collected in the high resolution mode $(>25,000$ FWHM).

\section{Target analysis}

PBDEs, MeO-PBDEs and OH-PBDEs were analyzed by gas chromatography (GC)-electron capture negative ion chemical ionization (ECNI)-mass spectrometry (MS), ${ }^{5)}$ and the PBDDs were analyzed by GC-high resolution (magnetic sector)-MS. ${ }^{9)}$ The quantification was performed using peak areas, and all quantitative data are corrected for recovery of the internal standards (IS).

\section{RESULTS AND DISCUSSION}

\section{Evaluation of Br-scripts for $\mathrm{GC} \times \mathrm{GC}$ data}

The visual basic scripts extracted more than forty peaks from the peak table. Di-bromo, tri-bromo, tetra-bromo compounds and, to some extent penta-bromo compounds, were successful extracted by the scripts, while there was a lack of selectivity for the mono-bromo compounds. Their molecular ion clusters were lean on structural information that could be used to discriminate against non-brominated compounds and instrument background. For the highly brominated compounds the large mass defect caused a problem as it resulted in distorted (nominal mass) molecular ion isotopic distribution clusters. Figure 1 shows the $\mathrm{MeO}-\mathrm{PBDE}$ mass defect as a function of the number of bromines. At a degree of bromination above 5, the mass defect approaches and exceeds $-0.5 \mathrm{amu}$ and the signal starts to distribute between adjacent bins in the nominal mass spectrum, which results in a severe distortion of the bromine pattern (Fig. 1, right).

\section{Brominated phenolic compounds detected through automatic screening of $\mathrm{GC} \times \mathrm{GC}$ data using scripts}

The Diloma marine snails are lean on fat (1.5\% lipids), have low metabolic capacitiy, and feed on periphyton and sediment. They therefore rapidly equilibrate with and reflect their surroundings. The phenolic fraction of the tissue extract was very rich in natural phenolic compounds (detected as methyl derivatives). A 2D-chromatogram with peak markers shown in Fig. 2, top panel, illustrates its complexity (each black square represents a detected component). A characteristic pattern, indicating the presence of petroleum hydrocarbons, ${ }^{1)}$ was observed in the lower half of the chromatogram (second dimension retention times $0.2-0.7 \mathrm{~s}$ ). In $1 \mathrm{D}-\mathrm{GC}$, this would correspond to a big "hump" in the chromatogram that is commonly denoted UCM (unresolved

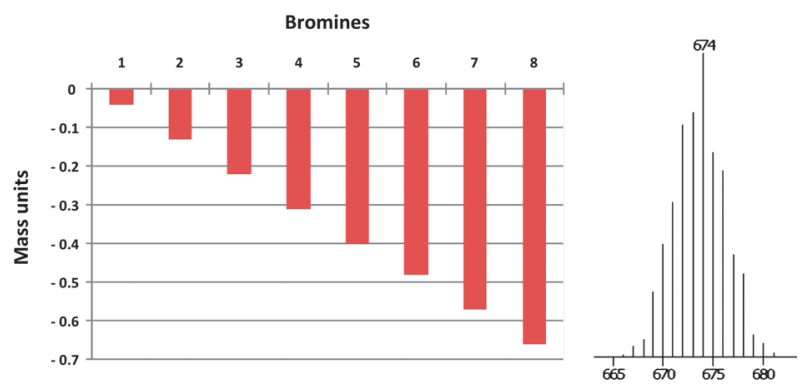

Fig. 1. Mass defects of MeO-PBDEs with increasing number of bromines, left. The observed effect on the (nominal mass) molecular ion isotope distribution clusters are illustrated, to the right, by a zoom-in on the molecular ion region of a $\mathrm{MeO}-\mathrm{HxBDE}\left(\mathrm{M}^{+}\right.$at $\left.m / z 668\right)$.

complex mixture). The chromatogram also contain horizontal bands from column bleed (second dimension retention times $>1.7 \mathrm{~s}$ and $<0.25 \mathrm{~s}$ with first dimension retention times $>1000 \mathrm{~s}$ ). These dominant features make manual 2D-chromatogram and peak table evaluation a daunting task.

Automatic peak table filtration using the di-bromo through tetra-bromo scripts automatically extracted a number of potential brominated compounds, indicated with green, yellow and red circles, respectively, in Fig. 2, middle panel. The two early eluting components were identified using the NIST 2011 MS library as a dibromoanisole (DiBA) and a tribromoanisole (TrBA), most likely from derivatized (methylated) 2,4-dibromophenol and 2,4,6-tribromophenol, both well-known HNPs. ${ }^{10)}$ Additional peaks were tentatively identified as $\mathrm{MeO}$-triBDEs (from $\mathrm{OH}$-triBDEs), $\mathrm{MeO}$ tetraBDEs (from $\mathrm{OH}$-tetraBDEs), a triBDD, and a tetraBDD using in-house generated EI spectrum. In the retention time region of $\mathrm{MeO}$-tetraBDEs, a compound tentatively assigned as a methyl-MeO-triBDE (Me-MeO-triBDE; from a $\mathrm{Me}-\mathrm{OH}$-triBDE) was also detected. Two additional peaks were tentatively assigned as $\mathrm{MeO}$-tetraBDDs (from $\mathrm{OH}$ tetraBDDs). The mass spectrum of one of these is shown in Fig. 3, top panel. Two additional tetra-bromo compounds were found, with (apparent) molecular weights of 446 and $454 \mathrm{~g} / \mathrm{mol}$, respectively. The occurrence of PBDDs was somewhat unexpected as the phenolic fraction should not contain neutral compounds. Their presence could indicate that the PBDD levels in the samples are very high and a small portion end up in the wrong (phenolic) fraction. The presence of a UCM in the chromatogram supports that idea.

Because of the systematic nature of the orthogonal separation (dispersion) of the components in $\mathrm{GC} \times \mathrm{GC}$ it is possible to predict the position of homologues on the $2 \mathrm{D}$-plane. For instance, all brominated compounds are well retained in the second dimension because of strong charge-transfer interactions with the phenyl-groups of the BPX-50 stationary phase. It is therefore logical that the tri- and tetra-bromo $\mathrm{MeO}-\mathrm{BDEs}$ and PBDDs line up along two parallel lines up in the upper right hand corner of the 2D-chromatogram (Fig. 2, middle panel). Manual search of the chromatographic region of interest revealed additional chemically related components, indicated with white circles in Fig. 2, lower panel, i.e. five $\mathrm{MeO}$-pentaBDEs, and one MeO-hexaBDE (from $\mathrm{OH}$-pentaBDEs and a $\mathrm{OH}$-hexaBDE).

Manual inspection of extracted ion chromatograms of homologous compounds revealed a few additional low 

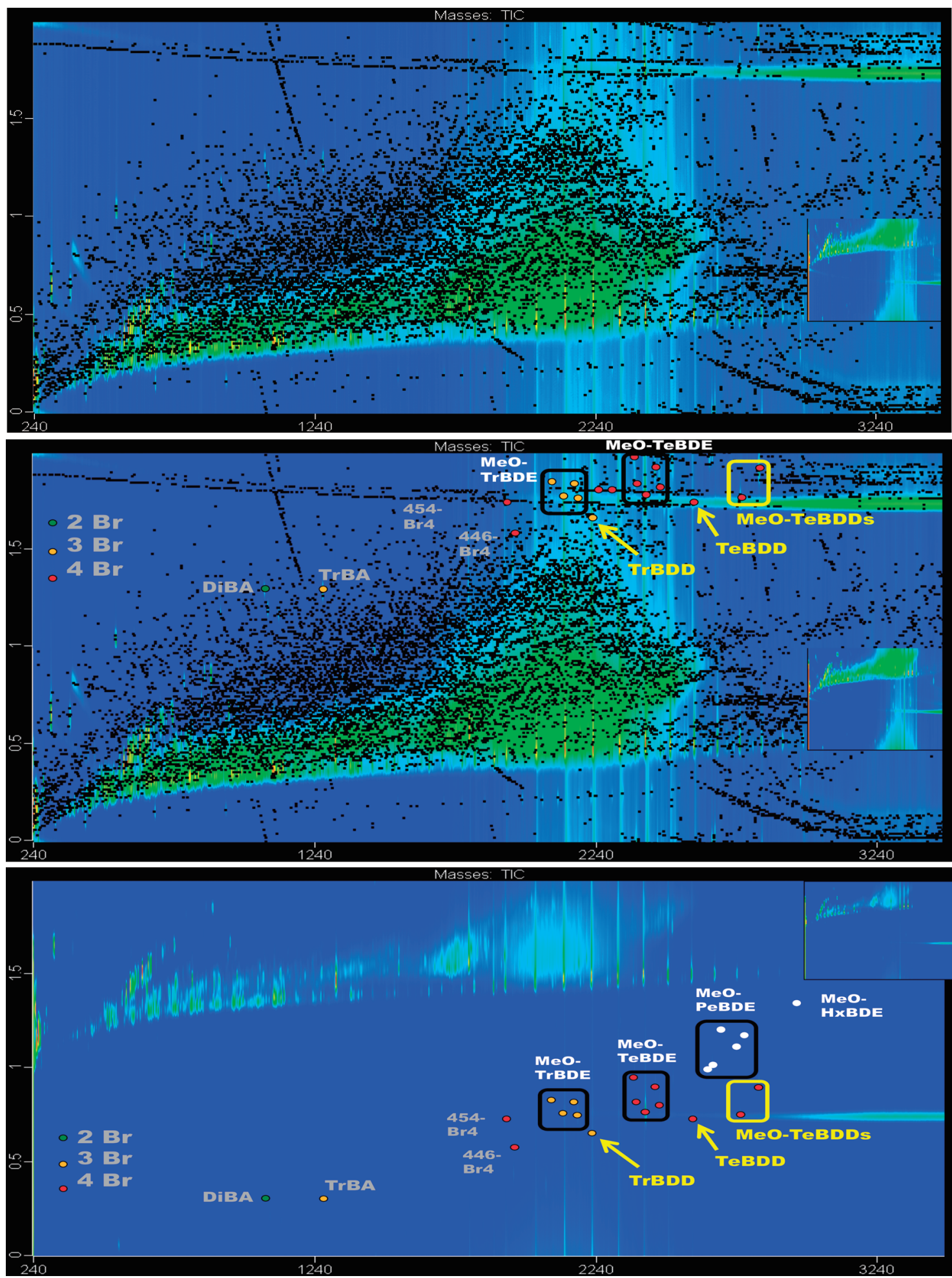

Fig. 2. $\mathrm{GC} \times \mathrm{GC}$ chromatograms of the methylated phenolics fraction of a marine snail (Diloma subrostrata) with peak markers, top panel. Peaks that were indicated as di-, tri-, and tetra-bromo substituted, respectively, by the corresponding Br-script, are indicated in the middle panel. Additional penta- and hexa-bromo compounds were found by manual search of suspected time regions. These are indicated with white circles in the lower panel ( $y$-axis was shifted by $1 \mathrm{~s}$ and the $z$-scale (intensity) was adjusted for enhanced visualization).

intensity components that were missed by the automatic Brscript filters. These were tentatively identified as, one $\mathrm{MeO}$ triBDE, one $\mathrm{Me}-\mathrm{MeO}$-triBDE, and one di-MeO-tetraBDE (from a di-OH-BDE or $\mathrm{OH}-\mathrm{MeO}-\mathrm{BDE}$ ). The intensity ratios of these were outside the acceptance criteria of the scripts.

\section{Evaluation of tentative structures using GC-high resolution TOF-MS}

Reanalysis of the samples at high resolution $(>25,000)$ confirmed the complexity of the sample. In 1D-GC, the chromatographic resolution is much lower and it was difficult to find all the tentatively identified brominated compounds. However, several were detected (limits of detection 

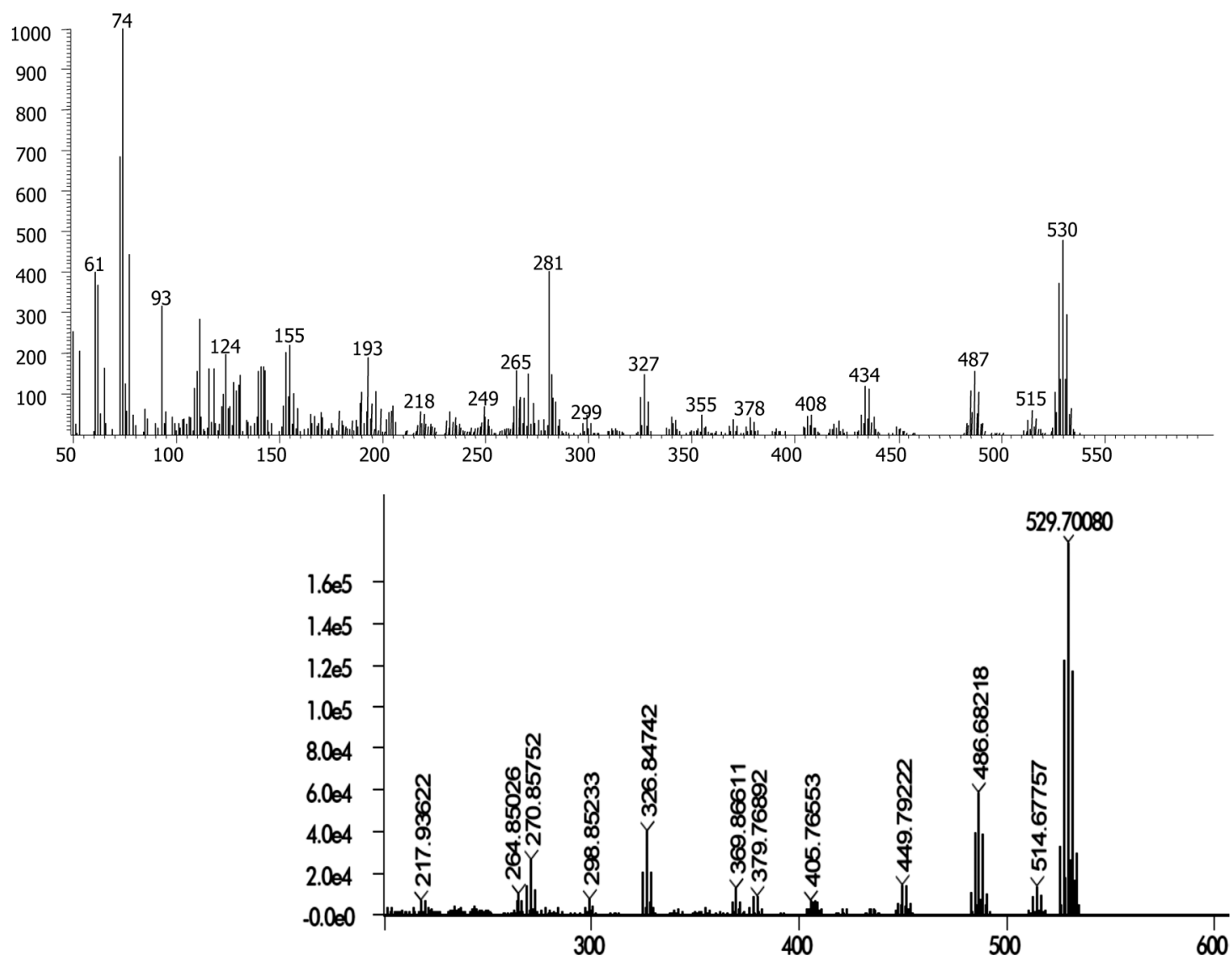

Fig. 3. EI spectra of a tetrabromo compound in the methylated phenolic fraction of a marine snail (Diloma subrostrata) using GC $\times$ GC-TOF-MS (low resolution) and GC-HRT (high resolution). The molecular ion mass $\left(\mathrm{m} / z\right.$ 525.7049) indicate an elemental composition of $\mathrm{C}_{13} \mathrm{H}_{6} \mathrm{O}_{3} \mathrm{Br}_{4}$ $(525.7050 \mathrm{~g} / \mathrm{mol})$, tentatively a MeO-TeBDD.

in the low pg range) and the GC-HRT accurate mass information generally agreed well with the tentative structure (Table 1). The relative errors were below $3 \mathrm{ppm}$ for most compounds, and below $1 \mathrm{ppm}$ for intense components. One of the MeO-tetraBDDs was far outside the expected mass tolerance (at $+69 \mathrm{ppm})$ and an alternative structure was proposed, Me-MeO-tetraBDE. The molecular ion mass of the other component tentatively identified as $\mathrm{MeO}$-tetraBDD was however in agreement (relative error $0.8 \mathrm{ppm}$ ) with the expected mass (Table 1 ). The primary fragments $[\mathrm{M}-\mathrm{CH} 3]^{+}$ and $[\mathrm{M}-\mathrm{COCH} 3]^{+}$were also in good agreement; with relative errors of $+1.4 \mathrm{ppm}$ and $+0.1 \mathrm{ppm}$, respectively (Fig. 3 , lower panel). In addition, one of the unknowns was tentatively identified as dimethoxy-tetrabromo benzene using the accurate mass spectral information.

\section{Quantitative analysis of selected brominated com- pounds}

Target analysis was performed for $\mathrm{OH}-\mathrm{PBDE}$ and some related brominated natural products and environmental contaminants to generate a basis for comparison. The results are given in Table 2. The OH-PBDEs were clearly the dominating brominated compounds in the samples. Their total concentration was close to $600 \mathrm{ng} / \mathrm{g}$ dry weight (d.w.), which is more than two orders of magnitude higher than that of MeO-PBDEs (2 ng/g d.w.), PBDDs (1.3 ng/g d.w.) and PBDEs $(0.96 \mathrm{ng} / \mathrm{g}$ d.w.). The relative contributions within each class of compounds varied widely, with $\mathrm{OH}-\mathrm{BDE} 68$ and $\mathrm{OH}$ BDE137, MeO-BDE47 and MeO-BDE68, 1,3,7-TrBDD and
1,3,7,9-TeBDD, and BDE99, as the major OH-PBDEs, MeOPBDEs, PBDDs and PBDE, respectively.

The Me-MeO-PBDEs (from Me-OH-PBDEs) and Di$\mathrm{MeO}-\mathrm{PBDE}$ (from OH-MeO-PBDE or di-OH-PBDE) were semi-quantified and found to be present at similar and three orders of magnitude lower concentrations, respectively, as compared to the HO-PBDEs. No polybrominated dibenzofurans (PBDFs) were detected.

\section{Sources and potential effects}

By the complementary use of GC $\times$ GC-TOF-MS and GCHR-TOF-MS a number of brominated compounds were identified or tentatively identified. The positively identified compounds include 2,4-dibromophenol (2,4-diBP), 2,4,6-tribromophenol (2,4,6-triBP), PBDEs, OH-PBDEs, MeO-PBDEs, and PBDDs.

PBDEs are generally considered to be of anthropogenic origin, primarily from their used as brominated flame retardants. ${ }^{19)}$ All the others are likely or potential HNPs. The two BPs are well-known HNPs, ${ }^{10)}$ and two MeO-PBDEs (MeO-BDE47 and MeO-BDE68) have been proven to be of biogenic origin. ${ }^{11)}$ The suggested formation for OH-PBDEs, including biosynthesis, ${ }^{12,13)}$ photolytic coupling of $\mathrm{PBs},{ }^{14)}$ and metabolism of PBDEs. ${ }^{15)}$ Similarly, two natural formation routes for PBDDs have been proposed enzymatic (bromoperoxidase) dimerization of $\mathrm{BPs}^{16)}$ and photolytic cyclization of OH-PBDEs. ${ }^{17,18)}$ There are also anthropogenic sources of PBDDs and PBDFs, ${ }^{19)}$ but the absence of PBDFs in the samples indicated that PBDDs were of natural origin. 
Table 1. Evaluation of low resolution GC×GC-TOF-MS tentative peak assignments using high-resolution GC-TOF-MS (GC-HRT).

\begin{tabular}{|c|c|c|c|c|c|c|}
\hline $\begin{array}{c}\mathrm{GC} \times \mathrm{GC} \text { nominal } \\
\text { mass, } \# \mathrm{Br}\end{array}$ & $\begin{array}{l}\mathrm{GC} \times \mathrm{GC} \text { tentative } \\
\text { assignment }\end{array}$ & GC-HRT exact mass & Possible formula & Relative error (ppm) & GC-HRT reassignment & $\begin{array}{l}\text { Original (underiva- } \\
\text { tized) species }\end{array}$ \\
\hline $434, \mathrm{Br} 3$ & MeO-triBDE \# 1 & 433.81494 & {$\left[\mathrm{C}_{13} \mathrm{H}_{9} \mathrm{O}_{2} \mathrm{Br}_{3}\right]^{+\bullet}$} & 0.5 & & OH-triBDE \\
\hline $434, \mathrm{Br} 3$ & MeO-triBDE \#2 & 433.81488 & {$\left[\mathrm{C}_{13} \mathrm{H}_{9} \mathrm{O}_{2} \mathrm{Br}_{3}\right]^{+\bullet}$} & 0.4 & & OH-triBDE \\
\hline $434, \mathrm{Br} 3$ & $\mathrm{MeO}$-triBDE \#3 & 433.81473 & {$\left[\mathrm{C}_{13} \mathrm{H}_{9} \mathrm{O}_{2} \mathrm{Br}_{3}\right]^{+\bullet}$} & 0.0 & & OH-triBDE \\
\hline $434, \mathrm{Br} 3$ & MeO-triBDE \#4 & 433.81518 & {$\left[\mathrm{C}_{13} \mathrm{H}_{9} \mathrm{O}_{2} \mathrm{Br}_{3}\right]^{+\bullet}$} & 1.2 & & OH-triBDE \\
\hline $434, \mathrm{Br} 3$ & MeO-triBDE \#5 & 433.81578 & {$\left[\mathrm{C}_{13} \mathrm{H}_{9} \mathrm{O}_{2} \mathrm{Br}_{3}\right]^{+\bullet}$} & 2.4 & & OH-triBDE \\
\hline $448, \mathrm{Br} 3$ & $\mathrm{Me}-\mathrm{MeO}$-triBDE & 447.83067 & {$\left[\mathrm{C}_{14} \mathrm{H}_{11} \mathrm{O}_{2} \mathrm{Br}_{3}\right]^{+\bullet}$} & 0.7 & & Me-OH-triBDE \\
\hline $450, \mathrm{Br} 4$ & Unknown & 449.70813 & {$\left[\mathrm{C}_{8} \mathrm{H}_{6} \mathrm{O}_{2} \mathrm{Br}_{4}\right]^{+\bullet}$} & -3.2 & $\mathrm{Di}-\mathrm{MeO}-\mathrm{TeBz}$ & Di-OH-tetraBz \\
\hline $512, \mathrm{Br} 4$ & MeO-tetraBDE \# 1 & 511.72582 & {$\left[\mathrm{C}_{13} \mathrm{H}_{8} \mathrm{O}_{2} \mathrm{Br}_{4}\right]^{+\bullet}$} & 1.1 & & OH-tetraBDE \\
\hline $512, \mathrm{Br} 4$ & $\mathrm{MeO}$-tetraBDE \#2 & 511.72589 & {$\left[\mathrm{C}_{13} \mathrm{H}_{8} \mathrm{O}_{2} \mathrm{Br}_{4}\right]^{+\bullet}$} & 1.3 & & $\mathrm{OH}$-tetraBDE \\
\hline $512, \mathrm{Br} 4$ & MeO-tetraBDE \#3 & 511.72498 & {$\left[\mathrm{C}_{13} \mathrm{H}_{8} \mathrm{O}_{2} \mathrm{Br}_{4}\right]^{+\bullet}$} & -0.5 & & OH-tetraBDE \\
\hline $512, \mathrm{Br} 4$ & MeO-tetraBDE \#4 & 511.72568 & {$\left[\mathrm{C}_{13} \mathrm{H}_{8} \mathrm{O}_{2} \mathrm{Br}_{4}\right]^{+\cdot}$} & 0.9 & & OH-tetraBDE \\
\hline $526, \mathrm{Br} 4$ & MeO-tetraBDD & 525.74138 & {$\left[\mathrm{C}_{14} \mathrm{H}_{10} \mathrm{O}_{2} \mathrm{Br}_{4}\right]^{+\bullet}$} & $69 *(0.6)$ & Me-MeO-tetraBDE & Me-OH-tetraBDE \\
\hline $526, \mathrm{Br} 4$ & MeO-tetraBDD & 525.70492 & {$\left[\mathrm{C}_{13} \mathrm{H}_{6} \mathrm{O}_{3} \mathrm{Br}_{4}\right]^{+\bullet}$} & 0.8 & & OH-tetraBDD \\
\hline $542, \mathrm{Br} 4$ & Di-MeO-tetraBDE & 541.73625 & {$\left[\mathrm{C}_{14} \mathrm{H}_{10} \mathrm{O}_{3} \mathrm{Br}_{4}\right]^{+\bullet}$} & 0.8 & & Di-OH-tetraBDE \\
\hline $590, \operatorname{Br} 5$ & MeO-pentaBDE & 589.6365 & {$\left[\mathrm{C}_{13} \mathrm{H}_{7} \mathrm{O}_{2} \mathrm{Br}_{5}\right]^{+\bullet}$} & 1.3 & & $\mathrm{OH}$-pentaBDE \\
\hline
\end{tabular}

* The GC-HRT exact mass did not match the tentative MeO-tetraBDD structure (elemental composition) and it was reassigned as a Me-MeO-tetra$\mathrm{BDE}$. The relative errors were calculated versus both $\mathrm{MeO}$-tetraBDD and $\mathrm{Me}-\mathrm{MeO}$-tetraBDE (in parenthesis).

Table 2. Concentrations of brominated compounds in marine snails (Diloma subrostrata) in pg/g dry weight.

\begin{tabular}{|c|c|c|c|c|c|}
\hline \multicolumn{2}{|c|}{ PBDEs } & \multicolumn{2}{|c|}{$\mathrm{OH} / \mathrm{MeO}-\mathrm{BDEs}$} & \multicolumn{2}{|c|}{ PBDDs } \\
\hline BDE47 & 92 & $\mathrm{MeO}-\mathrm{BDE} 47$ & 1200 & 13-DBDD & 4.0 \\
\hline BDE66 & 99 & MeO-BDE68 & 500 & 27/28-DBDD & 33 \\
\hline BDE99 ${ }^{\#}$ & 560 & MeO-BDE85 & 90 & 17-DBDD & 4.9 \\
\hline BDE100 & 75 & MeO-BDE90 & $<30$ & 18-DBDD & 17 \\
\hline BDE153 & 73 & MeO-BDE99 & 230 & 137-TrBDD & 170 \\
\hline BDE154 & 40 & MeO-BDE123 & $<40$ & 138-TrBDD & 93 \\
\hline BDE183 & $<20^{*}$ & MeO-BDE137 & $<80$ & 147-TrBDD & 11 \\
\hline \multirow[t]{10}{*}{$\Sigma \mathrm{PBDE}$} & 960 & $\Sigma \mathrm{MeO}-\mathrm{PBDE}$ & 2000 & 237-TrBDD & 0.93 \\
\hline & & & & 1368-TeBDD & 19 \\
\hline & & OH-BDE47 & 43000 & 1379-TeBDD & 870 \\
\hline & & OH-BDE68 & 120000 & 1378-TeBDD & 8.7 \\
\hline & & OH-BDE85 & 38000 & 1247/1248-TeBDD & 80 \\
\hline & & OH-BDE90 & 73000 & 2378-TeBDD & 12 \\
\hline & & OH-BDE99 & 70000 & 1237-TeBDD & $<0.05$ \\
\hline & & OH-BDE123 & 28000 & 1238-TeBDD & $<0.05$ \\
\hline & & OH-BDE137 & 220000 & PBDFs & n.d. ${ }^{*}$ \\
\hline & & $\Sigma \mathrm{OH}-\mathrm{PBDE}$ & 590000 & $\Sigma \mathrm{PBDD}$ & 1300 \\
\hline
\end{tabular}

* Not detected groups of compounds are denoted n.d., while the limits-of-quantification (LOQ) is given for individual compounds (<LOQ). ${ }^{\#}$ Potential co-elution with 5-Cl-6-MeO-BDE47.

The same may then be true for the OH-tetraBDD. Reports of $\mathrm{OH}$-tetraBDDs in marine sponge from the area provide indirect support for that idea. ${ }^{20)}$

$\mathrm{Me}-\mathrm{OH}$-triBDEs and $\mathrm{Me}-\mathrm{OH}$-tetraBDEs have to our knowledge not previously been detected in biological samples. A closely related $\mathrm{Me}-\mathrm{MeO}$-tetraBDE were however recently isolated from whale blubber in sufficient amounts for structure elucidation using NMR. Its structure was found to be $6-\mathrm{MeO}-5-\mathrm{Me}-\mathrm{BDE} 42 .^{21)}$ It is plausible that the detected tetrabromo compounds are the corresponding $\mathrm{Me}-\mathrm{OH}-$ tetraBDE. However, it cannot be excluded that it (at least in part) stem from $\mathrm{Me}-\mathrm{MeO}-\mathrm{BDE}$ that were not efficiently removed during the cleanup process (as was the case for two high level PBDDs). In future studies it is recommended to use a complementary derivatization agent to produce, e.g. ethyl-derivatives. That would rule out such ambiguities.

Many of the brominated compounds detected are biologically active. Phenolic compounds, including OH-PBDEs, can uncouple the oxidative phosphorylation in fish, ${ }^{22}$ and the 2,3,7,8-tetraBDD bind tightly to the dioxin-(Ah)receptor and induce dioxin-like effects in mammals. ${ }^{23)}$ The concentration of the latter was $12 \mathrm{pg} / \mathrm{g}$ dry weight, which corresponds to $c a .2 .5 \mathrm{pg}$ dioxin toxic equivalents (TEQ)/g fresh weight, assuming same toxicity of brominated and chlorinated isomers. This is slightly below the maximum residue level in EU fish (4 pg TEQ/g fresh weight). Mollusks have been part of the traditional diet (kai) of the indigenous Mauri population of New Zealand and people that consume large quantities of shellfish will be exposed to these brominated compounds.

\section{CONCLUSION}

Scripting tools can be used to extract information about the presence of di- through tetrabromo compounds from extensive peak and spectra tables. There are however room for improvements. The script for extraction of peaks with monobromo and penta- through octabromo isotope distribution patterns failed due to limited selectivity and spectral distortion (of nominal mass data), respectively. These problems could be avoided by using high resolution MS data or narrower digitalization bins $(0.1 \mathrm{amu}$ bin widths would suffice). The ordered structure of 2D-chromatograms from properly tuned $\mathrm{GC} \times \mathrm{GC}$ column set does partially alleviate these problems. Based on the relative position of a series of homologous compounds it is possible to predict where 
closely related (smaller or larger) congeners would elute and manually search these retention time regions.

Tentative identification is often possible using EI library searching or a priori knowledge about likely constituents in the environmental samples under study. It is also possible to perform manual spectral interpretation of full-scan EI spectra (that are usually free of interferences due to the high peak capacity of GC $\times$ GC). Further analysis using high resolution GC-TOF-MS offers a highly complementary set of data that can be used to test the validity of the tentative structure assignments. When the initial assignment does not hold, the accurate mass information can be used to find alternative candidates that, ultimately, may be verified by comparison to authentic reference standards.

To further streamline this type of identification procedure it would be desirable to combine $\mathrm{GC} \times \mathrm{GC}$ with highresolution TOF-MS and adopt the scripting tools to handle high-resolution data (currently not available for GC-HRT). Soft ionization would also be highly useful as a substantial percentage of the GC amenable compounds do not produce (or produce low abundance) molecular ions upon electron ionization.

\section{Acknowledgements}

Greg Olsen, NIWA (National Institute of Water and Atmospheric Research Ltd.), Auckland, New Zealand is gratefully acknowledged for providing the Diloma sample.

David Alonso, LECO Corporation, Saint Joseph, Michigan is gratefully acknowledged for operational assistance with the GC-HRT.

\section{REFERENCES}

1) J. Beens, U. A. T. Brinkman. The role of GC in compositional analyses in the petroleum industry. Trends Analyt. Chem. 19: 260-275, 2000.

2) M. Harju, C. Danielsson, P. G. C. Haglund. Comprehensive two-dimensional gas chromatography of the 209 polychlorinated biphenyls. J. Chromatogr. A 1019: 111-126, 2003.

3) E. Hoh, S. J. Lehotay, K. Mastovska, H. L. Ngo, W. Vetter, K. C. Pangallo, C. M. Reddy. Capabilities of direct sample introduction comprehensive two-dimensional gas chromatography-timeof-flight mass spectrometry to analyze organic chemicals of interest in fish oils. Environ. Sci. Technol. 43: 3240-3247, 2009.

4) L. Hovander, M. Athanasiadou, L. Asplund, S. Jensen, E. K. Wehler. Extraction and cleanup methods for analysis of phenolic and neutral organohalogens in plasma. J. Anal. Toxicol. 24: 696-703, 2000.

5) K. Löfstrand, A. Malmvärn, P. Haglund, A. Bignert, Å. Bergman, L. Asplund. Brominated phenols, anisoles, and dioxins present in blue mussels from the Swedish coastline. Environ. Sci. Pollut. Res. 17: 1460-1468, 2010.

6) G. Marsh, R. Stenutz, A. Bergman. Synthesis of hydroxylated and methoxylated polybrominated diphenyl ethers-Natural products and potential polybrominated diphenyl ether metabolites. Eur. J. Org. Chem. 14: 2566-2576, 2003.

7) P. Moreira Bastos, P. Haglund. The use of comprehensive two-dimensional gas chromatography and structure-activity modeling for screening and preliminary risk assessment of organic contaminants in soil, sediment, and surface water. J. Soils Sediments 12: 1079-1088, 2012.

8) D.C Hilton. Automated screening for hazardous components in complex mixtures based on functional characteristics identifieable in GC $\times$ GC-TOF-MS data. Current Trends Mass Spectrom. July, 28 (2007).

9) P. Haglund. On the identity and formation routes of environmentally abundant tri- and tetrabromodibenzo-p-dioxins. Chemosphere 78: 724-730, 2010.

10) C. Flodin, F. Whitfield. Biosynthesis of bromophenols in marine algae. Water Sci. Technol. 40: 53-58, 1999.

11) E. L. Teuten, L. Xu, C. M. Reddy. Two abundant bioaccumulated halogenated compounds are natural products. Science 307: 917-920, 2005.

12) N. K. Utkina, M. V. Kazantseva, V. A. Denisenko. Brominated diphenyl ethers from the marine sponge Dysidea fragilis. Chem. Nat. Prod. 23: 508, 1987.

13) A. Malmvärn, Y. Zebühr, L. Kautsky, Å. Bergman, L. Asplund. Hydroxylated and methoxylated polybrominated diphenyl ethers and polybrominated dibenzo-p-dioxins in red alga and cyanobacteria living in the Baltic Sea. Chemosphere 72: 910-916, 2008.

14) H. Liu, H. Zhao, X. Quan, Y. Zhang, S. Chen, H. Zhao. Formation of 2'-hydroxy-2,3',4,5'-tetrabromodipheyl ether $\left(2^{\prime}-\mathrm{HO}\right.$ BDE68) from 2,4-dibromophenol in aqueous solution under simulated sunlight irradiation. Chemosphere 84: 512-518, 2011.

15) S. B. Wiseman, Y. Wan, H. Chang, X. Zhang, M. Hecker, P. D. Jones, J. P. Giesy. Polybrominated diphenyl ethers and their hydroxylated/methoxylated analogs: Environmental sources, metabolic relationships, and relative toxicities. Mar. Pollut. Bull. 63: 179-188, 2011.

16) K. Arnoldsson, P. L. Andersson, P. Haglund. Formation of environmentally relevant brominated dioxins from 2,4,6,-tribromophenol via bromoperoxidase-catalyzed dimerization. Environ. Sci. Technol. 46: 7239-7244, 2012.

17) P. O. Steen, M. Grandbois, K. McNeill, W. A. Arnold. Photochemical formation of halogenated dioxins from hydroxylated polybrominated diphenyl ethers (OH-PBDEs) and chlorinated derivatives (OH-PBCDEs). Environ. Sci. Technol. 43: 4405-4411, 2009.

18) K. Arnoldsson, P. L. Andersson, P. Haglund. Photochemical formation of polybrominated dibenzo- $p$-dioxins from environmentally abundant hydroxylated polybrominated diphenyl ethers. Environ. Sci. Technol. 46: 7567-7574, 2012.

19) I. Watanabe, S. Sakai. Environmental release and behavior of brominated flame retardants. Environ. Int. 29: 665-682, 2003.

20) N. K. Utkina, V. A. Denisenko, O. V. Scholokova, M. V. Virovaya, A. V. Gerasimenko, D. Y. Popov, V. B. Krasokhin, A. M. Popov. Spongiadioxins A and B, two new polybrominated dibenzo- $p$-dioxins from an Australian marine sponge Dysidea dendyi. J. Nat. Prod. 64: 151-153, 2001.

21) M. Unger, L. Asplund, G. Marsh, Ö. Gustafsson. Characterization of an abundant and novel methyl- and methoxy-substituted brominated diphenyl ether isolated from whale blubber. Chemosphere 79: 408-413, 2010.

22) A. L. Van Boxtel, J. H. Kamstra, P. H. Cenijn, B. Pieterse, M. J. Wagner, M. Antink, K. Krab, B. Van den Burg, G. Marsh, A. Brouwer, et al. Microarray analysis reveals a mechanism of phenolic polybrominated diphenylether toxicity in zebrafish. Environ. Sci. Technol. 42: 1773-1779, 2008.

23) L. S. Birnbaum, D. F. Staskal, J. J. Diliberto. Health effects of polybrominated dibenzo- $p$-dioxins (PBDDs) and dibenzfurans (PBDFs). Environ. Int. 29: 855-860, 2003. 